\title{
UJI AKTIVITAS EKSTRAK AIR AKAR MANIS (Glycyrrhiza glabra L.) SEBAGAI PENYUBUR RAMBUT PADA KELINCI JANTAN
}

\section{HAIR GROWTH ACTIVITY TEST OF WATER EXTRACT LIQUARICE (Glycyrrhiza glabra L.) IN RABBIT MALE}

\author{
Sulistiorini Indriaty ${ }^{1}$, Lela Sulastri ${ }^{1}$ \\ ${ }^{1}$ Akademi Farmasi Muhammadiyah Cirebon \\ Jl. Cideng Indah no. 3 Cirebon \\ Email : lovelykalila@yahoo.co.id \\ Email : lelasulastri79@yahoo.co.id
}

\begin{abstract}
ABSTRAK
Akar manis (Glycyrrhiza glabra L.) mengandung glisirisin dan flavonoid sebagai penyubur rambut. Penelitian ini bertujuan untuk mengetahui apakah ekstrak air akar manis dapat menyuburkan rambut pada kelinci jantan dengan membuat enam area: area I kontrol normal, area II kontrol negatif, area III kontrol positif, area IV dioleskan ekstrak air akar manis konsentrasi 2,5\%, area V dioleskan ekstrak air akar manis konsentrasi 5\%, dan area VI dioleskan ekstrak air akar manis konsentrasi 7,5\%. Pengolesan dilakukan dua kali sehari yaitu pada pagi dan sore $1 \mathrm{ml}$ pada tiap daerah pengolesan. Pengamatan dilakukan selama 35 hari dengan mengambil enam helai rambut kelinci pada tiap area setiap tujuh hari sekali yaitu hari ke-7, 14, 21, 28 dan ke-35. Rambut diambil dengan cara dicukur dan diukur dengan menggunakan jangka sorong. Pada hari ke-35, rambut pada tiap area dipotong dan ditimbang beratnya. Data yang diperoleh diolah secara statistik dengan metode ANOVA Penelitian dilakukan dengan mengukur laju pertumbuhan rambut dan bobot rambut selama 35 hari. Dari penelitian ini disimpulkan konsentrasi ekstrak air akar manis $2,5 \%$ memiliki efek sebagai penyubur rambut dengan laju pertumbuhan rambut terbaik yaitu 2,19 $\mathrm{cm}$ dalam 35 hari, dan konsentrasi 5\% memiliki bobot rambut terbesar yaitu 0,12 gram dalam 35 hari.
\end{abstract}

Kata kunci : Akar manis, laju pertumbuhan rambut, bobot rambut, kelinci

\begin{abstract}
Liquorice (Glycyrrhiza glabra L.) containing glisirisin and flavonoids as fertilizer hair. This study aims to determine whether the water extracts of liquorice can nourish the hair on male rabbits by making six areas: area I normal control, area II negative control, the positive control area III, IV area applied water extract of liquorice concentration of $2.5 \%$, area $\mathrm{V}$ applied water extract of liquorice concentration of $5 \%$, and the area VI applied water extract of liquorice concentration of $7.5 \%$. Basting is done twice a day, morning and evening $1 \mathrm{ml}$ of each area basting. Observations made during 35 days by taking six strands of hair rabbits in each area every seven days ie day 7, 14, 21, 28 and 35th. Hair taken by sheared and measured using calipers. On the 35th day, in every area of hair cut and weighed. The data obtained were processed statistically by ANOVA methods The study was conducted by measuring the rate of hair growth and hair weight for 35 days. This study suggests the concentration of water extracts of liquorice $2,5 \%$ has the effect as fertilizer hair with the best hair growth rate is $2.19 \mathrm{~cm}$ in 35 days, and the concentration of $5 \%$ has the biggest hair weight is 0.12 grams in 35 days.
\end{abstract}


\begin{tabular}{l|l} 
Uji Aktivitas Ekstrak Akar Manis.... & 25
\end{tabular}

Sulistiorini Indriaty dkk

Keywords: Liquorice, the rate of hair growth, hair weights, rabbit

PENDAHULUAN

Kerontokan rambut adalah kehilangan rambut terminal dalam bentuk apapun dan dimanapun asal mula terjadinya yang berkisar lebih dari 100 helai per hari, dapat terjadi difus atau lokal. Kelainan setempat dapat berupa unifokal atau multifokal, bila kerontokan ini berlanjut dapat terjadi alopesia (kebotakan) (Erdina, 2002). Cara mengatasi kebotakan adalah dengan memberikan nutrisi atau vitamin rambut pada kulit kepala secara rutin. Dengan diberikannya vitamin rambut, diharapkan rambut kembali tumbuh normal seperti biasa, salah satu tanaman yang dapat digunakan untuk mengatasi kerontokan rambut adalah akar manis.

Beberapa komponen telah diisolasi dari akar manis termasuk senyawa yang larut air meliputi triterpen, saponin, flavonoid, polisakarida, pektin, asam amino, gula, garam mineral. Glisirizin yang termasuk dalam triterpenoid merupakan senyawa triterpenoid glikosida yang larut air tersusun dari campuran garam kalium kalsium magnesium asam glisirizin yang memberikan rasa manis pada akar manis yang jumlahnya berkisar 2-25\%.

Glisirizin mengandung bagian yang hidrofilik, 2 molekul asam glukoronik dan bagian hidropobik yaitu asam gliseretik. Warna kuning pada akar manis disebabkan karena kandungan flavonoid yang terdiri atas likuiritin, isolikuiritin ( kalkon). Isoflavon glabridin dan hispaglabirin A dan B memiliki aktivitas antioksidan selain itu glabridin dan glabrene memiliki aktivitas seperti estrogen (Kumar,2012).

Pengaruh pemberian akar manis sebagai penumbuh rambut pada tikus betina telah dilakukan dengan cara menggunduli punggung tikus tersebut kemudian dibagi menjadi tiga kelompok. Bahan yang digunakan adalah minyak parafin (kontrol), $2 \%$ larutan minoxidil dan petroleum eter $\left(60-80^{\circ} \mathrm{C}\right)$ ekstrak akar Glycyrrhiza glabra (2\%) selama 30 hari, diamati secara visual pertumbuhan rambut kelinci. Setelah itu biopsi kulit diambil untuk evaluasi kepadatan folikel dan fase pertumbuhan rambut. Kesimpulan penelitian ini menunjukkan bahwa ekstrak petroleum eter akar Glycyrrhiza glabra memiliki potensi sebagai penumbuh rambut pada tikus betina (Sukirti, 2012).

Ekstrak akar manis lebih efektif dibandingkan minoxidil dalam merangsang pertumbuhan rambut pada tikus betina. Jika sepenuhnya dikembangkan akan memiliki potensi melebihi minoxidil yang saat ini banyak digunakan untuk perangsang pertumbuhan rambut dan dikategorikan sebagai obat gaya hidup (Kunte, 2010). Pada penelitian ini ingin diketahui apakah ekstrak air akar manis yang bersifat polar memiliki aktivitas sebagai penyubur rambut.

\section{METODE PENELITIAN}

\section{Alat dan Bahan}

Alat- alat yang digunakan yaitu neraca analitik (RADWAG ${ }^{\circledR}$ AS 160/C/2), jangka sorong, gunting rambut, dan spatula. Sedangkan bahan yang digunakan adalah ekstrak air akar manis diperoleh dari PT. Tri Rahardja (Java Plant) yang sudah dalam bentuk serbuk kering, dan aqua destilata (Pro Teknis CV. Mustika Lab).

\section{Hewan uji}

Penelitian ini menggunakan hewan kelinci jantan putih usia 3-4 bulan dengan bobot badan 2-3 kg. Jumlah kelinci yang digunakan dihitung dengan menggunakan rumus empiris Federer, (n-1) (t-1) $\geq 15$, dimana $t$ menunjukkan jumlah perlakuan dan n merupakan jumlah hewan tiap perlakuan (Juhaeni , 2014; Priskila, 2012) sehingga kelinci yang digunakan adalah 4 ekor. 


\section{Jalannya Penelitian}

1. Pembuatan larutan ekstrak akar manis

Dalam $1 \mathrm{~kg}$ ekstrak, mengandung maltodeksin $25 \%$ dan akar manis $75 \%$. Pembuatan konsentrasi ekstrak akar manis dilakukan sebagai berikut:

a. Konsentrasi 2,5\%

Ekstrak air akar manis 3,33 gram dilarutkan dengan aquades hingga $100 \mathrm{ml}$

b. Konsentrasi $5 \%$

Ekstrak air akar manis 6,67 gram dilarutkan dengan aquades hingga $100 \mathrm{ml}$

c. Konsentrasi 7,5\%

Ekstrak air akar manis 10 gram dilarutkan dengan aquades hingga $100 \mathrm{ml}$

2. Persiapan hewan uji

Hewan uji yang digunakan pada penelitian ini adalah kelinci jantan yang berumur 3 - 4 bulan sebanyak 4 kelinci dengan berat 2 - $3 \mathrm{~kg}$. Sebelum diberi perlakuan kelinci diadaptasikan terlebih dahulu selama seminggu supaya tidak terjadi stress.

3. Uji aktivitas penyubur rambut

Pengujian efektivitas penyubur rambut dari ekstrak air akar manis terhadap kelinci menggunakan metode Tanaka et al. Terlebih dahulu dilakukan pencukuran rambut di punggung kelinci. Punggung kelinci dibersihkan dari rambutnya dengan membuat 6 daerah dengan bentuk segi empat dengan lebar sisi 2,5 x 2,5 cm dan jarak antar daerah $1 \mathrm{~cm}$. Sebelum dilakukan pengolesan ekstrak punggung kelinci diolesi etanol $70 \%$ sebagai antiseptik. Bagian daerah tersebut adalah:

$\mathrm{X} 1$ : diolesi dengan ekstrak air akar manis dengan konsentrasi $2,5 \%$.

$\mathrm{X} 2$ : diolesi dengan ekstrak air akar manis dengan konsentrasi $5 \%$.

$\mathrm{X} 3$ : diolesi dengan ekstrak air akar manis dengan konsentrasi 7,5\%

$\mathrm{X} 4$ : kontrol normal (tidak diolesi apapun)

$\mathrm{X} 5$ : kontrol negatif ( aquadest)

X6 : kontrol positif (sediaan penumbuh rambut yang ada dipasaran)

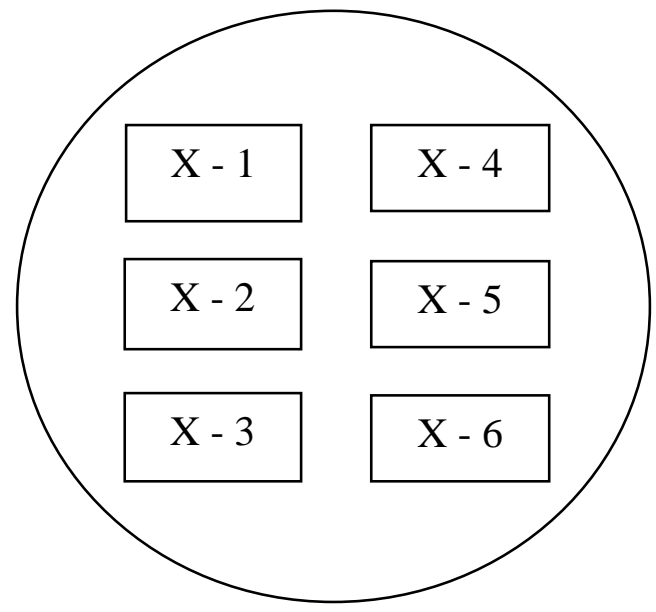

Gambar 3.1 Daerah X 1 - X 6 diacak posisinya untuk tiap kelinci.

Pengolesan dilakukan dua kali sehari yaitu pada pagi dan sore hari masing-masing $1 \mathrm{ml}$ pada tiap daerah pengolesan. Pengamatan dilakukan selama 35 hari dengan mengambil enam helai rambut kelinci pada tiap bagian setiap tujuh hari sekali yaitu hari ke-7, ke-14, ke-21, ke-28 dan ke-35. Hari pertama pengolesan dianggap hari ke-0. Rambut diambil dengan cara dicukur, kemudian diluruskan dan diletakkan pada alas berwarna gelap serta diselotip dan diukur dengan menggunakan jangka sorong. Pada hari ke-35, rambut pada area dipotong dan ditimbang beratnya. (Purwantini, 2008). 


\section{Analissis Data}

Data yang diperoleh dari hasil penelitian diolah secara statistik dengan Uji Homogenitas dan Normalitas dilanjutkan dengan uji ANOVA, Kruskall Wallis dan Uji Mann Whitney dengan taraf kepercayaan 95\%, untuk membandingkan enam kelompok pengujian, yaitu kelompok kontrol normal (tanpa pengolesan apapun), kelompok kontrol negatif (aquades), kelompok kontrol positif (sediaan penumbuh rambut yang ada dipasaran), dan kelompok perlakuan (ekstrak air akar manis dengan konsentrasi $2,5 \%, 5 \%$ dan $7,5 \%$ ).

\section{HASIL DAN PEMBAHASAN}

Uji aktivitas pertumbuhan rambut dilakukan pada 6 kelompok uji, yaitu konsentrasi ekstrak 2,5\%, konsentrasi ekstrak 5\%, konsentrasi ekstrak 7,5\%, kontrol normal, kontrol negatif dan kontrol positif. Kontrol normal merupakan kelompok yang hanya dicukur rambutnya tanpa pengolesan sediaan. Rambut dicukur bukan dicabut, agar rambut bisa tumbuh secara alami setelah pencukuran dilakukan. Kontrol negatif merupakan kelompok yang diberikan aquadestilata. Hal ini dimaksudkan untuk melihat apakah aquadestilata memberikan pengaruh pada pertumbuhan rambut. Perbedaan konsentrasi ekstrak adalah untuk melihat konsentrasi mana yang memiliki aktivitas optimal meningkatkan pertumbuhan rambut kelinci dan yang menghasilkan bobot rambut paling berat. Ketiga formulasi ini juga dibandingkan dengan kontrol normal, kontrol negatif dan kontrol positif.

Pengujian dilakukan pada kelinci jantan. Pemilihan kelinci jantan adalah karena kelinci jantan lebih adaptif terhadap lingkungan dan tidak mudah stress yang dapat mempengaruhi efek pertumbuhan rambut.

Laju pertumbuhan rambut kelinci yang diberi ekstrak akar manis dengan konsentrasi 2,5\%, 5\% dan 7,5\% dapat dilihat pada tabel berikut:

Tabel I. Laju pertumbuhan rambut yang diberi ekstrak akar manis hari ke-0 sampai ke-35

\begin{tabular}{lccccc}
\hline & \multicolumn{5}{c}{ Panjang rambut kelinci $(\mathrm{cm})$ hari ke- \pm SD } \\
\cline { 2 - 6 } Perlakuan & 7 & 14 & 21 & 28 & 35 \\
\hline $\begin{array}{l}\text { Ekstrak akar manis } \\
\text { konsentrasi 2,5\% }\end{array}$ & 0 & $0,64 \pm 0,39$ & $0,93 \pm 0,31$ & $1,91 \pm 0,44$ & $2,19 \pm 0,42$ \\
$\begin{array}{l}\text { Ekstrak akar manis } \\
\text { konsentrasi 5\% }\end{array}$ & 0 & $0,85 \pm 0,83$ & $1,19 \pm 0,58$ & $1,95 \pm 0,45$ & $2,18 \pm 0,39$ \\
$\begin{array}{l}\text { Ekstrak akar manis } \\
\text { konsentrasi 7,5\% }\end{array}$ & 0 & $0,62 \pm 0,39$ & $1,16 \pm 0,60$ & $1,84 \pm 0,93$ & $2,13 \pm 0,98$ \\
Kontrol Normal & & & & & \\
Kontrol Negatif & 0 & $0,38 \pm 0,07$ & $0,64 \pm 0,10$ & $1,39 \pm 0,28$ & $1,59 \pm 0,23$ \\
Kontrol Positif & 0 & $0,36 \pm 0,02$ & $0,68 \pm 0,13$ & $1,42 \pm 0,25$ & $1,56 \pm 0,23$ \\
\hline & 0 & $0,86 \pm 0,50$ & $1,11 \pm 0,09$ & $1,85 \pm 0,14$ & $2,02 \pm 0,12$ \\
\hline
\end{tabular}

Pada hari ke-0 sampai hari ke-7 belum mengalami pertumbuhan rambut, karena rambut memerlukan nutrisi serta waktu untuk mengalami pertumbuhan rambut. Berdasarkan data tabel di atas dapat disimpulkan bahwa konsentrasi 2,5\% merupakan konsentrasi dengan laju pertumbuhan rambut terbaik selama 35 hari yaitu 2,19 cm. Dikuti dengan konsentrasi $5 \%$ yaitu 2,18 cm dan konsentrasi 7,5\% yaitu $2,13 \mathrm{~cm}$. Berikut ini adalah grafik laju pertumbuhan rambut : 


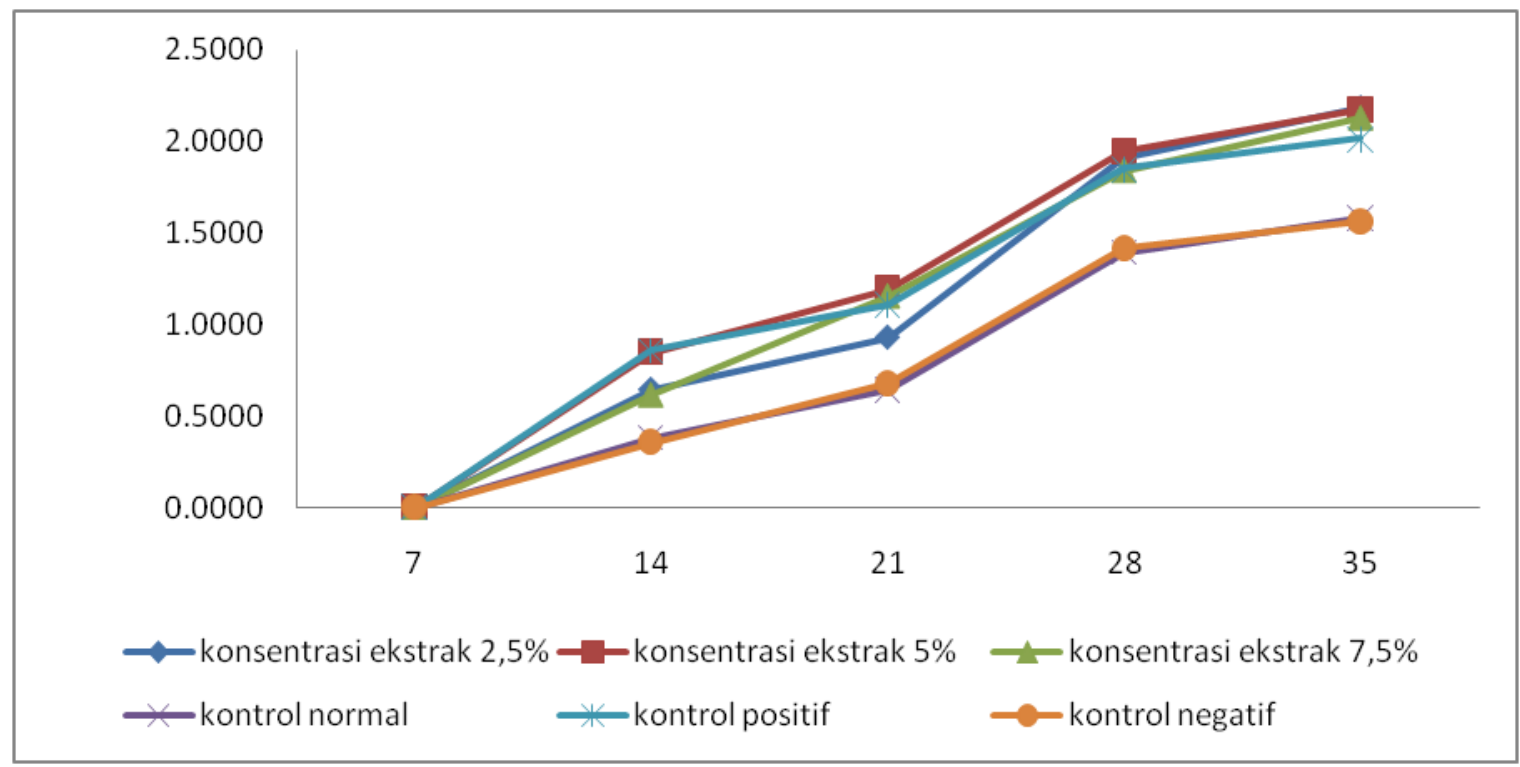

\section{Gambar 1. Laju pertumbuhan rambut pada hari ke-7 hingga hari ke-35}

Hasil statistik menunjukkan data terdistribusi normal tetapi tidak homogen. Uji Kruskal Wallis menunjukkan tidak terdapat perbedaan signifikan antar kelompok perlakuan $(\alpha>0,05)$. Pada uji Mann Whitney konsetrasi ekstrak akar manis 2,5\% menunjukkan perbedaan signifikan terhadap kontrol normal $(\alpha<0,05)$ dan ekstrak akar manis konsentrasi 5\% menunjukkan perbedaan signifikan terhadap kontrol negatif $(\alpha<0,05)$ sehingga aktivitasnya lebih bagus dari kontrol negatif. Tetapi ketiga konsentrasi akar manis tersebut tidak memiliki perbedaan signifikan terhadap kontrol positif, sehingga dapat disimpulkan aktivitas pada pertumbuhan rambut sama dengan kontrol positif.

Rata-rata bobot rambut kelinci ekstrak akar manis pada hari ke-35 dapat dilihat sebagai berikut:

Tabel II. Bobot rambut kelinci pada hari ke-35

\begin{tabular}{ccccccc}
\hline & \multicolumn{7}{c}{ Bobot rambut kelinci $(\mathrm{g})$} \\
\cline { 2 - 7 } & \multicolumn{7}{c}{ Perlakuan } \\
\cline { 2 - 7 } Kelinci & $\mathrm{A}$ & $\mathrm{B}$ & $\mathrm{C}$ & $\mathrm{D}$ & $\mathrm{E}$ & $\mathrm{F}$ \\
\cline { 2 - 7 } & 0,084 & 0,1425 & 0,1479 & 0,0647 & 0,0648 & 0,0743 \\
2 & 0,0754 & 0,2167 & 0,0684 & 0,0295 & 0,0642 & 0,095 \\
3 & 0,1705 & 0,0957 & 0,0561 & 0,1327 & 0,1589 & 0,0745 \\
4 & 0,0048 & 0,0061 & 0,0077 & 0,009 & 0,0125 & 0,0304 \\
rata-rata & 0,0837 & 0,1153 & 0,0700 & 0,0589 & 0,0751 & 0,0686 \\
SD & 0,0679 & 0,0882 & 0,0582 & 0,0543 & 0,0610 & 0,0272 \\
\hline
\end{tabular}

Keterangan :
A : Ekstrak akar manis konsentrasi 2,5\%
D : Kontrol normal
B : Ekstrak akar manis konsentrasi 5\%
E : Kontrol positif
C : Ekstrak akar manis konsentrasi 7,5\%
$\mathrm{F}:$ Kontrol negatif 
Berdasarkan tabel diatas dapat disimpulkan bahwa konsentrasi 5\% merupakan konsentrasi terbaik dengan rata-rata bobot terberat selama 35 hari yaitu 0,1153 gram. Diikuti dengan konsentrasi 2,5\% yaitu 0,0837 gram dan kontrol positif yaitu 0,0751 gram. Berikut ini grafik bobot rambut :

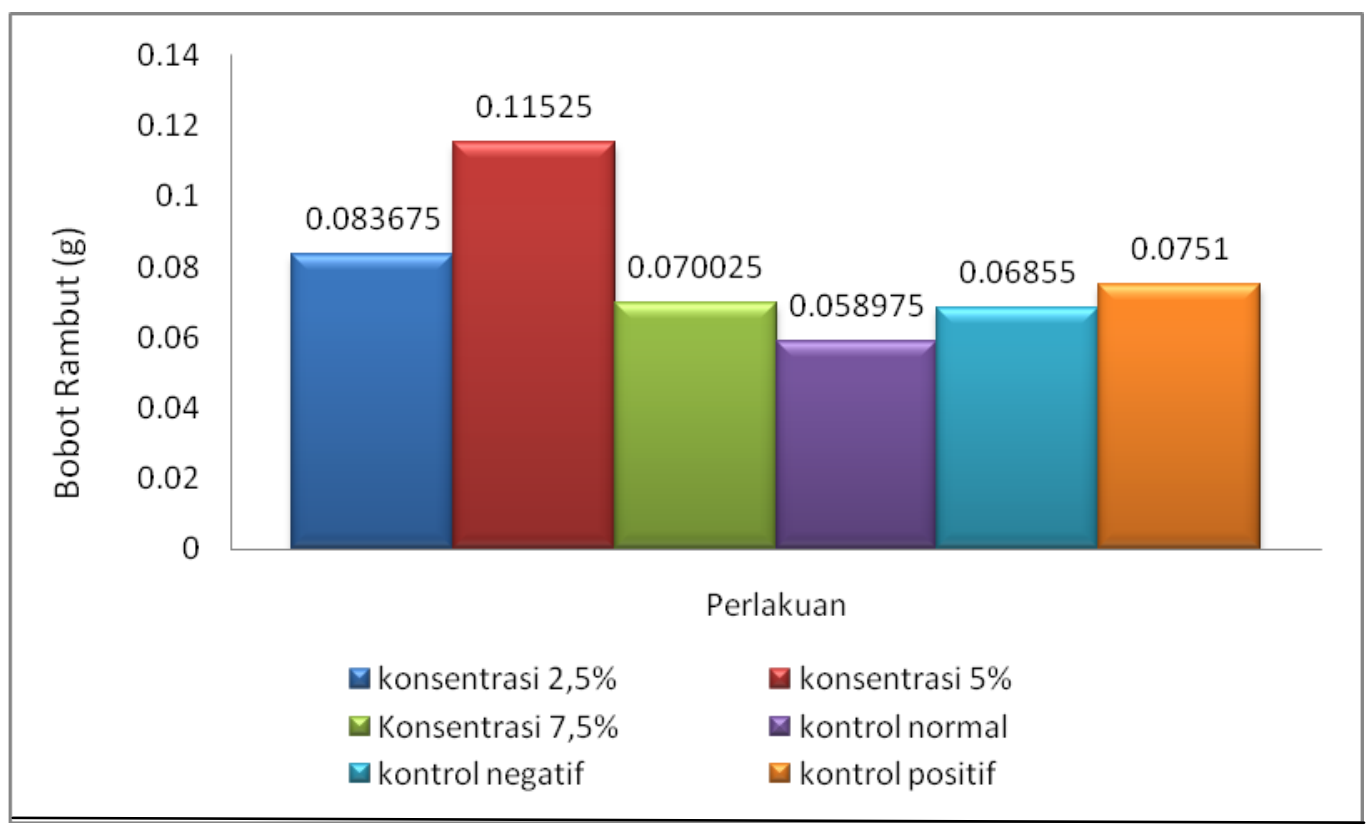

\section{Gambar 2. Bobot rambut kelinci pada hari ke-35}

Bobot rata-rata rambut kelinci pada hari ke-35 menunjukkan bahwa Konsentrasi 5\% memiliki bobot paling berat diantara kelompok perlakuan lainnya (Gambar 4.2). Kemudian diolah secara statistik untuk mengetahui adanya perbedaan yang bermakna dari tiap kelompok perlakuan. Hasil pengolahan data secara statistik menunjukkan bahwa rata-rata bobot rambut terdistribusi dengan normal dan homogen, oleh karena itu pengujian dilakukan dengan Uji ANOVA. Hasil uji ini menunjukkan tidak terdapat perbedaan bermakna pada kontrol normal ataupun kontrol negatif dibandingkan dengan konsentrasi 2,5\%, konsentrasi 5\%, konsentrasi 7,5\% (p<0,05). Hal ini menunjukkan bahwa konsentrasi 2,5\%, konsentrasi $5 \%$ dan konsentrasi 7,5\% pada hari ke-35 tidak memiliki aktivitas sebagai penyubur rambut.

\section{KESIMPULAN}

Ekstrak air akar manis dengan konsentrasi 2,5\% memiliki laju pertumbuhan rambut yang terbesar yaitu $2,1858 \mathrm{~cm}$ dan konsentrasi $5 \%$ memiliki bobot rambut terbesar yaitu $0,11525 \mathrm{~g}$.

\section{DAFTAR PUSTAKA}

Erdina H.D., dkk. 2002. Kesehatan dan Keindahan Rambut. Jakarta: Kelompok Studi Dermatologi Kosmetik Indonesia

Juheini, A., Esther L.P.S., Anwar, E., Djajadisastra, J., 2014, Green Tea (Camellia Sinensis, L.) Ethanolic Extract as Hair Tonic in Nutraceutical:Physical Stability, Hair Growth Activity on Rats, and Safety Test, International Journal of Pharmacy and Pharmaceutical Sciences.6( 5).94-99 
\begin{tabular}{l|l} 
Uji Aktivitas Ekstrak Akar Manis.... & 30
\end{tabular}

Sulistiorini Indriaty dkk

Kumar, anil. Dora jyotsna.Review on Glycyrrhiza glabra (Liquorice). Journal of Pharmaceutical and Scientific Innovation. 2012; 1(2): 1-4

Kunte Y, Sucklecha A, Rahman SJ, Life style drug concept and impact on society, 2010,Indian Journal Pharmaceutical Sciences; 72(4): 409-413

Priskila, V., 2012. Uji stabilitas fisik dan uji aktivitas pertumbuhan rambut tikus putih jantan dari sediaan hair tonik yang mengandung ekstrak air bonggol pisang kepok (musa balbisiana) (Skripsi). Depok : Fakultas MIPA. Program studi farmasi.28

Purwantini, I., Rima, M., Naniek, D.B.S., 2008, Combination Of Teh And Mangkokan Leaves Extract To Promote Hair Growth, Traditional Medicine Journal. 13(43)

Sukirti, U., Ashoke K.G., Vijender, S., 2012, Hair Growth Promotant Activity of Petroleum Ether Root Extract of Glycyrrhiza Glabra L (Fabaceae) in Female Rats, Tropical Journal of Pharmaceutical Research. October.11(5):753-758 